\title{
QUEIJO MINAS FRESCAL ENRIQUECIDO COM ÓLEO DE OREGANO
}

\author{
Joana Luiza Lima Farias', Priscila Lídia Rosa de Rezende', Ellen Godinho Pinto ${ }^{1}$ \\ ${ }^{1}$ Instituto Federal Goiano- Campus Morrinhos- GO. E-mail: ellen.godinho@ifgoiano.edu.br
}

\section{RESUMO}

O trabalho teve a finalidade de avaliar características físico-química e microbiológica do queijo enriquecido com óleo essencial de orégano durante o tempo de 21 dias. Foram produzidas três amostras de queijo, Controle (sem adição de óleo essencial de orégano), Q1(Adição de 0,01\%) e Q2(adição de 0,02\%). Realizou-se análise físico-química segundo Instituto Adolf Lutz (2008) de umidade, sólidos solúveis totais, acidez lática e lipólise. Os dados foram submetidos à ANOVA e teste de Tukey $(p \leq 0,05)$. As amostras foram analisadas microbiologicamente (aeróbios mesófilos, psicrotróficos, coliformes totais e a presença de salmonella) nos tempos 0, 7, 14 e 21 dias. As contagens para os microorganismos aeróbios mesófilos, psicrotróficos, coliformes e a ausência de salmonella encontraram-se dentro dos limites estabelecidos pela legislação. As baixas contagens demonstram condições de higiene satisfatórias, assim como armazenamento correto. O que permite concluir, que a inserção dos queijos enriquecido de óleo essencial de orégano no mercado consumidor é viável, nas concentrações avaliadas.

Palavras-chave: análise físico-química; microbiologia; química; shelf life.

\section{FRESH MINES CHEESE ENRICHED WITH OREGANO OIL}

\begin{abstract}
The objective of this work was to evaluate the physical, chemical and antimicrobial properties of the essential oil of oregano in cheese during the time of 21 days. Three samples of Control cheese (without addition of oregano essential oil), Q1 (Addition of 0,01\%) and Q2 (addition of 0,02\%) were produced. The water content, ash, total soluble solids, lactic acidity and lipolysis were evaluated according to the Adolf Lutz Institute (2008). Data were submitted to ANOVA and Tukey test $(p \leq 0,05)$. The samples were analyzed microbiologically (mesophilic aerobes, psychrotrophic, total coliforms and the presence of salmonella) at times $0,7,14$ and 21 days. The counts for the mesophilic, psychrotrophic, coliform aerobic microorganisms and the absence of salmonella were within the limits established by the legislation. Low counts demonstrate satisfactory hygiene conditions as well as correct storage. This leads us to conclude that the insertion of enriched cheeses of oregano essential oil in the consumer market is viable, at the concentrations evaluated. Keywords: Chemical physical analysis; microbiology; chemistry; shelf life.
\end{abstract}

\section{INTRODUÇÃO}

Queijo minas frescal é definido pela portaria no 352/976, como todo produto obtido por meio da coagulação enzimática do leite com coalho ou outras enzimas coagulantes apropriadas, complementado ou não com influência de bactérias láticas específicas (BRASIL, 1997).

Devido a vida-de-prateleira curta, o queijo minas frescal deve ser comercializado logo após fabricação, pois apresenta propensão a contaminações microbianas, que pode vir a acontecer a partir do leite empregado na produção deste ou por contaminações cruzadas durante ou após a 
fabricação. As contaminações podem ser decorrentes das próprias alterações fazendo que em pouco dias seja inaceitável para consumo ( ROCHA et al., 2006).

A contaminação em queijos, pode ocorrer por bactérias do grupo coliformes, salmonella spp., staphylococcus aureus, listeria monocytogenes sendo eles bio-indicadores de degradação do produto (PINTO et al., 2011).

A legislação demanda medidas para o controle do uso de aditivos empregados para conservação de alimentos, por consequência a um grande interesse em pesquisas pela busca de compostos alternativos para o emprego como conservante em alimentos (GUTIERREZ et al., 2009). A atividade antimicrobiana com o uso do óleo essencial de orégano, indica um desempenho positivo em combater o crescimento de micro-organismos patógenos e deteriorantes de alimentos, destacando-se as bactérias E. coli, L. monocytogenes e S. Aureus (CASTILHO et al., 2012).

Este trabalho tem como objetivo realizar análises físico-química e microbiológica de queijo minas frescal com adição de óleo essencial de orégano em diferentes concentrações.

\section{MATERIAL E MÉTODOS}

Os queijos foram produzidos no laboratório da Agroindústria no Instituto Federal Goiano, Câmpus Morrinhos, seguindo as boas práticas de fabricação.

Os ingredientes foram adquiridos no comércio local de Morrinhos-GO, com exceção do óleo de orégano adquirido em Goiânia-GO.

\section{Processamento do queijo}

Foram elaboradas três formulações de queijo, o controle sem adição de óleo essencial de orégano, o tratamento Q1 com adição de 0,01\% de óleo essencial de orégano e o tratamento Q2 com adição de $0,02 \%$ óleo essencial de orégano. Os queijos foram produzidos segundo metodologia proposta por Bezerra (2008) adaptada, sendo usando os seguintes ingredientes: $97,9 \%$ de Leite pasteurizado não homogeneizado, $0,1 \%$ de coalho, $2 \%$ de sal.

Os queijos foram submetidos, logo após a fabricação, às análise físico-químicas e microbiológicas e armazenados embalados sob refrigeração $\left(5 \pm 2^{\circ} \mathrm{C}\right)$ e analisadas nos tempos 0,7 , 14 e 21 dias.

\section{Controle microbiológico}

Foram realizadas análises de bactérias aeróbias mesófilas, psicrotróficas, coliformes totais e Salmonella ssp.

Para a pesquisa de Salmonella spp. os tratamentos de queijos controle e enriquecidos com óleo essencial foram sujeitas $\left(25 \mathrm{~g}+225 \mathrm{~mL}\right.$ de água peptonada) incubadas a $35^{\circ} \mathrm{C}$ por 24 horas, segundo a Portaria no 8 do Ministério da Agricultura, Pecuária e Abastecimento (BRASIL, 1997). O enriquecimento seletivo foi efetuado em caldo Tetrationato (TT), preparado conforme as instruções do fabricante, inoculando alíquotas de $1 \mathrm{~mL}$ das tratamentos homogeneizadas em $9 \mathrm{~mL}$ do caldo com incubação a $43^{\circ} \mathrm{C}$ por 24 horas, em banho-maria circular. Após o enriquecimento seletivo, alíquotas do meio TT foram estriadas em placas contendo ágar verde brilhante preparados conforme as instruções do fabricante. Ambas foram incubadas a $35^{\circ} \mathrm{C}$ por 24 horas em estufa bacteriológica (LOPES et al., 2007).

Realizou-se a técnica de plaqueamento em profundidade em meio Ágar Padrão para Contagem. As placas foram incubadas a $35^{\circ} \mathrm{C} / 48 \mathrm{~h}$ e $7^{\circ} \mathrm{C} / 7$ dias para determinação de mesófilos aeróbios e psicrotróficos, respectivamente (SAEKI; MATSUMOTO, 2010).

Para a análise de coliformes totais foram selecionadas as diluições $10^{-2}$ e $10^{-3}$ e as análises foram em triplicata. Inoculou-se as placas com meio para Escherichia coli (EC) com 1,0ml de cada tratamento, as mesmas foram identificadas e incubadas por 48 horas em estufa a $35^{\circ} \mathrm{C}$. 


\section{Análises físico-químicas}

Os tratamentos de queijos controle e enriquecidos com óleo essencial foram sujeitas às análises físico-químicas de: $\mathrm{pH}$, acidez titulável (\%de ácido lático) umidade, lipólise e SST (sólidos solúveis totais) seguindo a metodologia do Instituto Adolf Lutz (2004).

\section{Análise estatística}

Para a análise estatística foi aplicada a ANOVA e o teste de Tukey, num nível de significância de $5 \%$.

\section{RESULTADOS E DISCUSSÃO}

De acordo com a RDC no12 de 2 de janeiro de 2001, os limites microbiológicos para queijos com teor de umidade alto, temperados, condimentados ou adicionados de ervas ou outros ingredientes é de coliformes a 45 o C/g $10^{2} \mathrm{UFC} / \mathrm{g}$ e ausência Salmonella spp $25 \mathrm{~g}$.

Os resultados das contagens de mesófilos, psicrotróficos, coliformes totais e de Salmonella em tratamentos de queijo frescal estão apresentados na Tabela 1.

Tabela 1. Resultados microbiológicos dos queijo, nos tempos $0,7,14$ e 21 dias.

\begin{tabular}{|c|c|c|c|c|}
\hline \multirow[t]{2}{*}{ Tratamento } & \multicolumn{3}{|c|}{ Tempo (dias) } & \multirow[b]{2}{*}{21} \\
\hline & 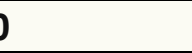 & 7 & 14 & \\
\hline \multicolumn{5}{|c|}{ Salmonela ssp. (UFC/g) } \\
\hline Controle & ausente & ausente & ausente & ausente \\
\hline Q1 & ausente & ausente & ausente & ausente \\
\hline Q2 & ausente & ausente & ausente & ausente \\
\hline \multicolumn{5}{|c|}{ Coliformes totais(UFC/g) } \\
\hline Controle & 3,74 & 3,74 & 5,10 & 5,10 \\
\hline Q1 & 3,74 & 1,6 & 1,6 & 1,6 \\
\hline Q2 & 2,2 & 1 & 1,6 & 1,6 \\
\hline \multicolumn{5}{|c|}{ Mesófilos(UFC/g) } \\
\hline Controle & $<10^{2}$ & $10^{2}$ & $>10^{2}$ & $>10^{3}$ \\
\hline Q1 & $10^{2}$ & $<10^{2}$ & $<10^{2}$ & $>10^{2}$ \\
\hline Q2 & $10^{2}$ & $10^{2}$ & $10^{2}$ & $>10^{2}$ \\
\hline \multicolumn{5}{|c|}{ Psicrotróficos (UFC/g) } \\
\hline Controle & $<10^{2}$ & $<10^{2}$ & $<10^{2}$ & $<10^{2}$ \\
\hline Q1 & $<10^{2}$ & $<10$ & $<10$ & $<10$ \\
\hline Q2 & $<10^{2}$ & $<10$ & $<10^{2}$ & $<10^{2}$ \\
\hline
\end{tabular}

A contagem de coliformes totais e psicrotróficos em todos os tempos e para todos os tratamentos estudados foi inferior $\mathrm{a}<10^{2} \mathrm{UFC} / \mathrm{g}$, valor este que se encontra conforme a legislação brasileira, que coloca como valor limite $10^{2} \mathrm{UFC} / \mathrm{g}$.

Todos os tratamentos analisados apresentaram ausência de Salmonella em $25 \mathrm{~g}$ de produto, este micro-organismo tem grande importância para saúde pública, assim o controle do mesmo em alimentos, está diretamente ligado à qualidade do produto

Hafemann et al. (2015) no que diz respeito à contagem total de micro-organismos aeróbios mesófilos, relata que é praticamente impossível obter contagens iguais a zero e que para produtos considerados frescos não se exige padrão para este grupo de micro-organismos, porém essa análise considerada como controle da microbiota.

Observou-se uma baixa contagem microbiana nos tratamentos Q1 e Q2, para coliformes totais, mesófilos e psicrotróficos, em relação ao tratamento controle, que apresentaram contagens mais altas, isso se deve ao óleo essencial de orégano ter ação antimicrobiana como foi observada por Hafemann et al. (2015) em ricota com adição de óleo essencial de orégano. 
Tabela 2. Médias das análises físico-químicas do queijo enriquecido de óleo essencial de orégano em diferentes tempos.

\begin{tabular}{|c|c|c|c|c|}
\hline \multirow[t]{2}{*}{ Tratamento } & \multicolumn{3}{|c|}{ Tempo (dias) } & \multirow[b]{2}{*}{21} \\
\hline & 0 & 14 & & \\
\hline \multicolumn{5}{|c|}{ Acidez lática } \\
\hline Controle & $0,053 \pm 0,006^{b^{*} B^{* *}}$ & $0,0356 \pm 0,002^{\mathrm{aB}}$ & $0,080 \pm 0,011^{\mathrm{aA}}$ & $0,09 \pm 0,005^{\mathrm{abA}}$ \\
\hline Q1 & $0,141 \pm 0,660^{\mathrm{aA}}$ & $0,041 \pm 0,006^{\mathrm{aB}}$ & $0,053 \pm 0,004^{\mathrm{bB}}$ & $0,066 \pm 0,007^{\mathrm{bB}}$ \\
\hline Q2 & $0,169 \pm 0,011^{\mathrm{aA}}$ & $0,053 \pm 0,000^{\mathrm{aA}}$ & $0,088 \pm 0,003^{\mathrm{aA}}$ & $0,0945 \pm 0,314^{\mathrm{aA}}$ \\
\hline \multicolumn{5}{|c|}{$\mathrm{pH}$} \\
\hline Controle & $6,83 \pm 0,020^{\mathrm{aA}}$ & $5,31 \pm 0,004^{a B}$ & $5,25 \pm 0,019^{a B}$ & $5,2 \pm 0,033^{\mathrm{aB}}$ \\
\hline Q1 & $6,73 \pm 0,003^{\mathrm{aA}}$ & $5,53 \pm 0,035^{\mathrm{aA}}$ & $5,37 \pm 0,009^{b A}$ & $5,27 \pm 0,030^{\mathrm{aA}}$ \\
\hline Q2 & $6,53 \pm 0,016^{\mathrm{aA}}$ & $5,25 \pm 0,024^{a B}$ & $5,24 \pm 0,019^{\mathrm{aB}}$ & $5,22 \pm 0,088^{a B}$ \\
\hline \multicolumn{5}{|c|}{ Sólidos solúveis totais } \\
\hline Controle & $9,5 \pm 0,133^{\mathrm{aC}}$ & $11 \pm 0,440^{\mathrm{aC}}$ & $14 \pm 0,440^{\mathrm{bB}}$ & $20 \pm 1,550^{\mathrm{aA}}$ \\
\hline Q1 & $10,2 \pm 0,130^{\mathrm{aC}}$ & $11 \pm 0,177^{\text {ac }}$ & $17 \pm 0,000^{\mathrm{aB}}$ & $25 \pm 0,880^{\mathrm{aA}}$ \\
\hline Q2 & $10,1 \pm 0,088^{\mathrm{aC}}$ & $11 \pm 0,000^{\mathrm{aBC}}$ & $17 \pm 0,044^{\mathrm{aB}}$ & $27 \pm 0,440^{\mathrm{aA}}$ \\
\hline \multicolumn{5}{|c|}{ Umidade } \\
\hline Controle & $68,71 \pm 0,002^{\mathrm{aA}}$ & $54,93 \pm 0,004^{\mathrm{aB}}$ & $53,33 \pm 0,009^{b B}$ & $51,78 \pm 0,020^{\mathrm{aB}}$ \\
\hline Q1 & $68,23 \pm 0,01^{\mathrm{aA}}$ & $55,79 \pm 0,0079^{a B}$ & $55,14 \pm 0,002 a^{b B}$ & $52,93 \pm 0,015^{\mathrm{aB}}$ \\
\hline Q2 & $56 \pm 0,01^{\mathrm{aA}}$ & $57,5 \pm 0,008^{\mathrm{aA}}$ & $55,98 \pm 0,09^{a A}$ & $51,05 \pm 0,008^{\mathrm{aA}}$ \\
\hline \multicolumn{5}{|c|}{ Lipólise } \\
\hline Controle & $0,282 \pm 0,0376^{\mathrm{aA}}$ & $0,1974 \pm 0,0188^{b B}$ & $0,282 \pm 0,0846^{\mathrm{aA}}$ & $0,282 \pm 0,280^{\mathrm{aA}}$ \\
\hline Q1 & $0,254 \pm 0,056^{\mathrm{aA}}$ & $0,197 \pm 0,018^{\mathrm{bB}}$ & $0,254 \pm 0,018^{\mathrm{aA}}$ & $0,2625 \pm 0,013^{\mathrm{aA}}$ \\
\hline Q2 & $0,197 \pm 0,0140^{\mathrm{aB}}$ & $0,4512 \pm 0,0282^{\mathrm{aA}}$ & $0,197 \pm 0,014^{\mathrm{aB}}$ & $0,205 \pm 0,02^{\mathrm{aB}}$ \\
\hline
\end{tabular}

*Médias acompanhadas de letras minúsculas iguais, na mesma coluna, não diferem entre si significativamente $(p \leq 0,05)$.

**Médias acompanhadas de letras maiúsculas iguais, na mesma linha, não diferem entre si significativamente $(\mathrm{p} \leq 0,05)$.

$\mathrm{Na}$ análise de acidez lática, no queijo controle, pode-se observar que aumentou com o passar dos dias, apresentando diferença significativa a partir do 14 dias. Porém, na tratamento Q2, não apresentou diferença significativa entre os dias de armazenamento. Sangaletti et al.(2009) encontraram também um acréscimo da acidez lática durante o armazenamento do queijo minas. O aumento da acidez está diretamente relacionado com o aumento da população dos microorganismos mesófilos, psicrotróficos e principalmente as bactérias lácticas, as quais são os principais agentes na transformação da lactose em ácido láctico

A redução do $\mathrm{pH}$ foi observada em todos os tratamentos em função do tempo de armazenamento, está redução também foi observada por Sangaletti et al.(2009) para queijo minas.

O teor de sólidos solúveis aumentou com o tempo de armazenamento variando de 9,5 a 27 ${ }^{\circ}$ Brix em todos os tratamentos. Pode-se observar que não houve diferença significativa entre os dois primeiros tempos estudados (0 e 7 dias). Porém, entre os tratamento não apresentaram diferença significativa, no mesmo tempo.

Com relação ao teor de água, não apresentou diferença significativa nos tratamentos estudados no mesmo tempo, entretanto apresentaram diferença significativa com o tempo zero das tratamento controle e Q1, porém o tratamento Q2 não apresentou diferença nos tempos, isso pode ter ocorrido devido o enriquecimento com óleo de orégano ter sido em uma concentração maior e evitando a perda de umidade. 
Os resultados de lipólise apresentaram um decréscimo no tempo de 7 dias e depois não apresentou diferença significativa com os demais tempos, porém para o tratamento Q2 apresentou uma situação inversa dos demais tratamentos, isso pode ter sido influenciado pelas bactérias psicrotróficas lipolíticas, as quais produzem enzimas lipolíticas.

\section{CONCLUSÕES}

Os parâmetros microbiológicos ficaram dentro dos padrões exigidos pela legislação brasileira vigente.

Assim, conclui-se que é viável a inserção no mercado de queijo com adição de óleo essencial de orégano, principalmente por este óleo funcionar como um conservante natural nos queijos descartando o uso de aditivos químicos.

\section{REFERÊNCIAS}

BEZERRA, J. R. M. V. Tecnologia de Fabricação de Derivados de leite. 1a Ed. Editora Unicentro. Guarapuava, 2008.

BRASIL. Ministério da Agricultura e do Abastecimento. Regulamentos Técnicos de Identidade e Qualidade do leite e produtos lácteos. Portaria $n^{\circ} 352$ de 04 de setembro de 1997. Diário Oficial da União, Brasília, DF, 08 set. 1997.

CASTILHO, P. C.; SAVLUCHINSKE-FEIO S.; WEINHOLD T. S.; GOUVEIA S. C.; Evaluation of the antimicrobial and antioxidant activities of essential oils, extracts and their main components from oregano from Madeira Island, Portugal. Food Control, v. 23, p. 552- 558, 2012. https://doi.org/10.1016/i.foodcont.2011.08.031

GUTIERREZ, J.; BARRY-RYAN, C.; BOURKE, P. Antimicrobial activity of plant essential oils using food model media: efficacy, synergistic potential and interactions with food components. Food Microbiology, v. 26, n. 2, p. 142-150, 2009. https://doi.org/10.1016/i.fm.2008.10.008

HAFEMANN, S .P. G., AVANÇO, G., SCAPIM, M. R. S., ANTIGO, J. L., POZZA, M. S. S., MADRONA, G. S. Ricota com adição de óleo essencial de orégano (origanum vulgare linneus): avaliação físico-química, sensorial e microbiológica. Revista Brasileira de Produtos Agroindustriais, v.17, n.3, p.317-323, 2015. https://doi.org/10.15871/1517-8595/rbpa.v17n3p317-323

INSTITUTO ADOLFO LUTZ. Métodos físico-químicos para análise de alimentos.4.ed. São Paulo: Instituto Adolfo Lutz, 2004.

LOPES, M., GALHARDO, J. A., OLIVEIRA, J. T., TAMANINI, R., SANCHES, S. F., MULLER, E. E. Pesquisa de Salmonella spp. e micro-organismos indicadores em carcaças de frango e água de tanques de pré-resfriamento em abatedouro de aves. Semina: Ciências Agrárias, v. 28, n. 3, p. 465-476, jul./set. 2007. https://doi.org/10.5433/1679-0359.2007v28n3p465

PINTO, F. G. S.; SOUSA, M.; MOURA, A. C. Qualidade Microbiológica de Queijo Minas Frescal Comercializado no Município de Santa Helena, Arquivos do Instituto Biológico, v.78, n.2, p.191198, 2011.

ROCHA, J. S.; BURITI, F. C. A.; SAAD, S. M. I. Condições de processamento e comercialização de queijo - de - Minas Frescal. Arq. Bras. Méd. Vet. Zootec. v. 58, n.2, 
p.236-272, 2006. https://doi.org/10.1590/S0102-09352006000200016

SAEKI, E. K., MATSUMOTO, L. S. Contagem de mesófilos e psicrotróficos em amostras de leite pasteurizado e UHT. Revista Instituto Latícinio. "Cândido Tostes", n. 377, v.65, p. 29-35, 2010.

SANGALETTI, N., PORTO, E., BRAZACA, S. G. C., YAGASAKI, C. A., DALLA DEA, R. C., SILVA, M.V. Estudo da vida útil de queijo Minas. Ciência Tecnologia de Alimentos, v. 29, n.2, p. 262-269, 2009. https://doi.org/10.1590/S0101-20612009000200004 